\title{
Minimum-cost planning of the multimodal transport of pipes with evolutionary computation
}

\author{
Begoña González ${ }^{1}$, Gabriel Winter ${ }^{1 a}$, José Maria Emperador ${ }^{1}$, Blas Galván ${ }^{1}$ \\ ${ }^{1}$ Institute of Intelligent Systems and Numerical Applications in Engineering (SIANI), Laboratory of Evolutionary Computation and Applications \\ (CEANI), University of Las Palmas de Gran Canaria, 35.017 Las Palmas de Gran Canaria, Spain
}

Received 3 May 2009, Accepted 10 August 2009

\begin{abstract}
Every day many kilometres of European highways are blocked by traffic jams. Congestion on roads and at airports adds the EU's fuel bill with a corresponding rise in pollution levels. In short, our present patterns of transport growth are unsustainable. One way of easing road congestion is to develop the efficient end-to-end movement of goods using two or more forms of transport in an integrated transport chain. We will focus on the multimodal transport problem that involves finding the most economical route in the distribution of cast iron ductile piping with or without mortar joint, both of different diameters and from different possible supply points to different points of destination over three transport networks, road, rail and sea, which may have routes in common. The orders are made for quantities in linear metres of pipes. The economic cost of the transport on the various routes is dependent on the number of lorries, freight wagons and platforms required, and as these quantities must be obviously integer numbers. In practical applications the search space is dimensionally very high, often there exist attractors into the search space due to the existence of multiple global optimum solutions, the cost function has discontinuities, many constraints, etc. The problem that has to be resolved is of great complexity, even using evolutionary algorithms. Our experience gained working several years in this optimization problem is described in this paper, to highlight that there is a need using evolutionary algorithms with certain learning ingredients and using strategies that progressively impose with more and more severity in the evolutionary optimization process the real scenario of the complex problem to get convergence to the global optimal solutions and simultaneously to obtain low computational cost total.
\end{abstract}

Key words: Minimum-cost planning, Multimodal transport problem, Evolutionary computation

\section{Introduction}

The transport problem that is considered here involves finding the most economical route in the distribution of cast iron ductile piping without mortar joint (CIDP) and cast iron ductile piping with mortar joint (CIDP-MJ), both of different diameters and from different possible supply points to different points of destination over three transport networks, road, rail and sea, which may have routes in common. The orders are made for quantities in linear metres $((\mathrm{lm})$ ) with or without mortar joints) and are prepared in (tied) bundles of piping 6 metres long. Thus, the orders for each type and diameter of pipe should be in quantities (lm) that are multiples of 6.

The various networks considered are comprised of nodes (some belonging to different networks at the same time) which we have classified as factory-nodes (pipe supply points) and demand-nodes which cover both route-endnodes (from which no product leaves for another destination point), and transhipment-nodes which can, in turn, satisfy a partial demand and serve as a link to another transhipment-node or to a route-end-node. A partial demand can be considered as a real order demand or as a fixed storage.

The transport cost, whether by road, rail or sea, of a certain amount or length (lm) of piping - of a certain type and specific diameter - is evaluated, for each route, by consi- dering the number of lorries, freight wagons or platforms respectively required for this route and the unit cost per lorry, freight wagon or platform respectively associated with it, regardless of whether the lorries, freight wagons or platforms are full or not.

Since the economic cost of the transport on the various routes is dependent on the number of lorries, freight wagons and platforms required, and as these quantities are obviously integer numbers, the problem that has to be resolved is of great complexity, even using mathematical methods based on elements of artificial intelligence (genetic algorithms, evolutive strategies, etc.).

In addition, as a node can belong to more than one of the three transport networks considered, piping can leave and/or arrive from/to a same node via different means of transport, with which we have a very high number of situations or possible combinations to take into account when searching for the optimal route. This becomes extremely complex if we bear in mind that the ordered pipes can be of different diameter and type and that pipes of different diameters can be transported on the one same lorry, wagon or platform. In this situation, and if the possibility is also contemplated of a partial unloading of material at a transhipment node, thought has also to be given to the correct placement of the piping to facilitate its unloading so as not to have to unload and reload the piping that will continue to another demand-node.

\footnotetext{
${ }^{\text {a }}$ Corresponding author: gabw@step.es
} 
Two factory-nodes have been considered. The cast iron ductile pipes without mortar joint are supplied from just one factory-node, while those with mortar joint can be supplied from both factory-nodes. Therefore, in this latter case, the selection of the most suitable factory-node to make the order from is contemplated amongst the optimal decisions to be obtained with the system.

The complexity of the multimodal transport system considered here lies in:

- Simultaneity of three different transport networks: we do not have just a road network, but also the possibilities of alternative routes by sea and/or rail.

- Specification of the various nodes and routes which comprise each of the networks considered.

- Each client can demand at the same time, in different physical places or demand-nodes, different amounts of piping of different types and of different diameters.

- The maximum full load of a lorry, freight wagon or platform depends on the type and diameter of the pipes to be transported. Thus, for each type and diameter of pipe the following will have to be taken into account:

1. Number of pipes per bundle.

2. Number of bundles per lorry, freight wagon and platform, respectively.

3. Weight of each bundle.

4. Volume of each bundle: length, height and width.

The filling of a means of transport (by availability of volume and weight) sometimes requires the use of nonstandard sized bundles with less pipes than would correspond to it by type and diameter.

\section{Intelligent system developed for the op- timal planning of multimodal transport}

A genetic algorithm (GA) has been used as an optimising tool, with selection and mutation, associated with an expert system (Galván and Winter [1]). Additionally, and in order to facilitate convergence to the global optimum, we have considered various stages in the optimisation which appreciably improve the performance of the optimiser. The fundamental items which describe the process carried out are as follows:

- Definition of the variables which comprise a possible solution (an individual or chromosome) of the GA considered. Thus, an individual will be made up of different variables which will be, for each cast iron ductile pipe of a certain class ' $k$ ' and a fixed diameter ' $k \mathrm{k}$ ' the different lengths of pipe $(\mathrm{lm})$ which are transported by road, rail or sea, from a departure node ' $\mathrm{i}$ ' to an arrival node ' $\mathrm{j}$ ' over a period of time ' $\mathrm{t}$ '. These different lengths are represented by: $x[\mathrm{i}][\mathrm{j}][\mathrm{k}][\mathrm{t}][\mathrm{kk}]$ if the transport is by road, $\mathrm{y}[\mathrm{i}][\mathrm{j}][\mathrm{k}][\mathrm{t}][\mathrm{kk}]$ if the transport is by rail, and $z[i][j][k][t][k k]$ if the transport is by sea.

- Definition of the objective function that we wish to minimise and which in our case consists of two parts:

- The penalizing function which for a given demand-node is responsible for verifying that the quantity of a product that arrives at it is equal to the sum of the quantity of the product demanded by that node itself plus the product quantity which leaves it for other nodes.
- The cost function, which calculates the cost in function of the number of lorries, freight wagons and platforms used in the transport.

- Application of the developed intelligent system called Flexible Evolution Algorithm (FEA) (Winter et al. [2, 3, 4]). The FEA is subdivided into several functions, called 'engines'. These subroutines have been designed to group the diverse actions that are to be executed during the optimisation depending on their objectives. In this way, all the learning tasks will be clustered in a 'learning engine', and something similar will happen with all the selection schemes, sampling strategies or decision mechanisms. A general scheme of the Flexible Evolution Agent can be seen in Figure 1.

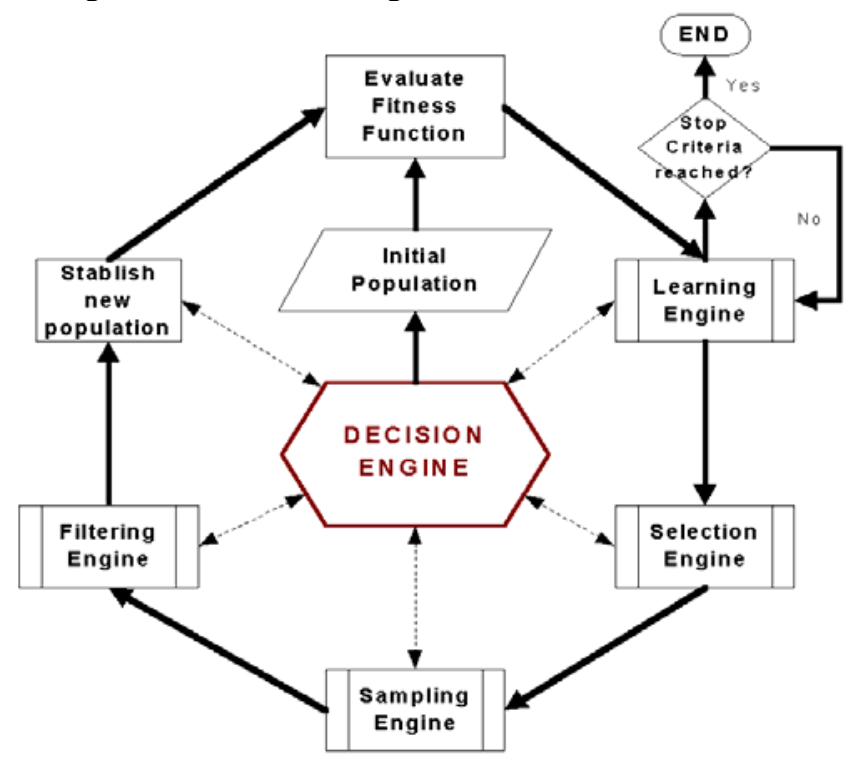

Fig. 1. Scheme of a Flexible Evolution Agent (FEA)

Starting with the initial population IP, and for all the iterations of the population obtained earlier, we evaluate the fitness function of each candidate solution and from here, and for each generation, the Decision Engine acts over all the different stages of the algorithm. So the decision engine will decide what kind of learning, selection and/or sampling strategy will be used in every generation until the stop criterion is reached, which is also determined by the Decision Engine. The Learning Engine stores everything that could be useful afterwards, such as information about the variables or statistics. The intention is to use this information to learn about the process and even to establish rules that could be fruitful and will be included in the decision engine afterwards.

The Selection Engine chooses which solutions are to be sampled and the sampling method that will be used, whereas the sampling engine carries out the mutation and crossover processes over the variables. Finally, the Filtering Engine removes the possible errors in the solutions before entering in the next iteration.

Main ingredients of the implementation of the FEA are: a Dynamic Structure of Operators (DSO), an Enlargement of the Genetic Code (EGC) of individuals and the use of a Central Control Mechanism (CCM). In order to obtain an efficient DSO two unique classes of operators have been 
defined: Selection and Sampling. Most existing crossover and mutation operators have been included in the Sampling class and the definition of two additional characteristics of all members of this class was also advisable: the Nature and the Range. The DSO enables the use of any of the operators at each step along every optimisation run depending on operator's previous contribution to the common task (to get the optimum). The genetic code of the individuals must be enlarged (EGC) in order to include useful information for the process control included in the CCM. After several implementations, the identification of the sampling method used to obtain each variable of the individuals has proved to be the most useful information, but only when a simple Probabilistic Control Mechanism (PCM) based on rules IFTHEN-ELSE is used as a CCM. The joint use of the DSO, the EGC and the CCM has permitted the elimination of the crossover and mutation probabilities. The PCM is responsible for reaching a trade-off between the exploration and the exploitation of the search space, which is equivalent to achieving a competitive and cooperative balance among the sampling operators.

Normally an evolutionary algorithm converge to a final population consists of the global optimum and solutions close to it. This causes difficulty when the function to optimize has multiple identical optimum solutions because in these problems there exist many attractors in which the algorithm can became directed to. To find different global optimum solutions we have incorporate in our Flexible Evolution Algorithm selection operators with sharing function proposed by Goldberg and Richardson [5].

In order to help the genetic algorithm in convergence to the optimum in our problem, two different fitness functions (FF) have been considered which differ basically in the weight given to the cost function (CF) and the penalizing function $(\mathrm{PF})$ : finally, the penalizing function weighs more. In addition, in the first time steps, a linear cost function has been considered.

The first objective function considered was: $\mathrm{FF}=\mathrm{CF}+\mathrm{PF}$ and the second one was FF $=\mathrm{CF}(1+\mathrm{PF})$.

Table 1. Costs per lorry related to each route in the road network

\begin{tabular}{lll}
\hline Origin & Destination & Cost $(€)$ \\
\hline Germany & Bilbao & 1779.63 \\
Germany & Gijón & 2083.23 \\
Germany & León & 2177.07 \\
Germany & Vigo & 2562.20 \\
Germany & Porto & 2592.33 \\
Germany & Coimbra & 2573.70 \\
Germany & Lisbon & 2969.76 \\
Germany & Barcelona & 1589.42 \\
Germany & Lérida & 1766.40 \\
Germany & Madrid & 2240.66 \\
Germany & Salamanca & 2219.85 \\
Germany & Ciudad Real & 2471.35 \\
Germany & Valencia & 1995.02 \\
Germany & Murcia & 2258.03 \\
Germany & Málaga & 2717.11 \\
Germany & Seville & 2854.30 \\
Germany & Huelva & 2860.05 \\
Germany & Burgos & 1950.15
\end{tabular}

\begin{tabular}{|c|c|c|}
\hline Germany & Antwerp & 750.00 \\
\hline Bilbao & Gijón & 345.00 \\
\hline Bilbao & León & 412.85 \\
\hline Bilbao & Lérida & 533.60 \\
\hline Bilbao & Salamanca & 454.25 \\
\hline Bilbao & Ciudad Real & 672.75 \\
\hline Bilbao & Valencia & 727.95 \\
\hline Bilbao & Murcia & 915.40 \\
\hline Bilbao & Málaga & 1079.85 \\
\hline Bilbao & Seville & 1072.95 \\
\hline Bilbao & Huelva & 1079.85 \\
\hline Bilbao & Tarragona & 638.25 \\
\hline Bilbao & Burgos & 181.70 \\
\hline Gijón & Bilbao & 345.00 \\
\hline Gijón & León & 141.45 \\
\hline Porto & Coimbra & 218.50 \\
\hline Porto & Lisbon & 460.00 \\
\hline Coimbra & Porto & 218.50 \\
\hline Coimbra & Lisbon & 241.50 \\
\hline Lisbon & Porto & 460.00 \\
\hline Lisbon & Coimbra & 241.50 \\
\hline Valencia & Murcia & 277.15 \\
\hline Seville & Huelva & 108.10 \\
\hline Austria & Bilbao & 1779.63 \\
\hline Austria & Gijón & 2083.23 \\
\hline Austria & León & 2177.07 \\
\hline Austria & Vigo & 2562.20 \\
\hline Austria & Porto & 2592.33 \\
\hline Austria & Coimbra & 2573.70 \\
\hline Austria & Lisbon & 2969.76 \\
\hline Austria & Barcelona & 1589.42 \\
\hline Austria & Lérida & 1766.40 \\
\hline Austria & Madrid & 2240.66 \\
\hline Austria & Salamanca & 2219.85 \\
\hline Austria & Ciudad Real & 2471.35 \\
\hline Austria & Valencia & 1995.02 \\
\hline Austria & Murcia & 2258.03 \\
\hline Austria & Málaga & 2717.11 \\
\hline Austria & Seville & 2854.30 \\
\hline Austria & Huelva & 2860.05 \\
\hline Austria & Burgos & 1950.15 \\
\hline Barcelona & León & 901.60 \\
\hline Barcelona & Lérida & 179.40 \\
\hline Barcelona & Salamanca & 894.70 \\
\hline Barcelona & Ciudad Real & 932.65 \\
\hline Barcelona & Valencia & 401.35 \\
\hline Barcelona & Murcia & 678.50 \\
\hline Barcelona & Málaga & 1146.55 \\
\hline Barcelona & Seville & 1202.90 \\
\hline Barcelona & Huelva & 1079.85 \\
\hline Barcelona & Tarragona & 112.70 \\
\hline Barcelona & Burgos & 670.45 \\
\hline Madrid & León & 382.95 \\
\hline Madrid & Lérida & 179.40 \\
\hline Madrid & Salamanca & 243.80 \\
\hline Madrid & Ciudad Real & 218.50 \\
\hline Madrid & Valencia & 404.80 \\
\hline Madrid & Murcia & 461.15 \\
\hline Madrid & Málaga & 625.60 \\
\hline Madrid & Seville & 618.70 \\
\hline Madrid & Huelva & 726.80 \\
\hline Madrid & Burgos & 181.70 \\
\hline
\end{tabular}


Tarragona Madrid

614.10

\section{Test application and results}

A test application defined by the company COSTRUCTED S.A. (Winter et al. [6, 7], Gonzalez et al. [8]), together with the results obtained from the use of a first implementation of the Flexible Evolution Algorithm (FEA) (Winter et al. [2]) is presented.

A global network of 23 nodes of which two are factorynodes is considered. There are 76 existing connections between these nodes for the road network (Table 1), 7 connections for the rail network (Table 2) and 12 for the sea network (Table 3). All train routes are also possible by road (http://ceani.ulpgc.es/transporte.php). The cast iron ductile pipes without mortar joint are only produced at one of the factory-nodes (Germany), while those with mortar joints are produced at both factory-nodes (Germany and Austria). The costs associated with each route of the various networks are shown in Tables 1-3.

Table 2. Costs per wagon related to each route in the rail network

\begin{tabular}{llc}
\hline Origin & Destination & Cost $(€)$ \\
\hline Germany & Antwerp & 1002.80 \\
Germany & Bilbao & 1702.80 \\
Germany & Barcelona & 1520.20 \\
Germany & Madrid & 2142.80 \\
Austria & Bilbao & 1702.80 \\
Austria & Barcelona & 1520.20 \\
Austria & Madrid & 2142.80 \\
\hline
\end{tabular}

Table 3. Costs per platform (lorry on routes BarcelonaPalma and Valencia-Palma) related to each route in the maritime network

\begin{tabular}{llc}
\hline Origin & Destination & Cost $(€)$ \\
\hline Antwerp & Bilbao & 2260.00 \\
Antwerp & Gijón & 2260.00 \\
Antwerp & Vigo & 2260.00 \\
Antwerp & Porto & 2260.00 \\
Antwerp & Lisbon & 2260.00 \\
Antwerp & Barcelona & 2260.00 \\
Antwerp & Valencia & 2260.00 \\
Antwerp & Palma & 2260.00 \\
Antwerp & Málaga & 2260.00 \\
Antwerp & Seville & 2260.00 \\
Barcelona & Palma & 1430.00 \\
Valencia & Palma & 1430.00 \\
\hline
\end{tabular}

In addition to the costs which appear in Table 3, other sea freight costs have to be added for the case of departure from Antwerp; the origin terminal handling charge, loading, bundling, destination terminal handling charge, goods handling charge, destination handling, etc. In the case of departure from Barcelona or Valencia to Palma, the destination terminal handling charge (165.00 Euros/lorry), goods handling charge (4.23 Euros/mt) and destination handling (100.00 Euros/lorry) have to be added.
Table 4 shows the pipe demand from the demand-nodes considered, and Tables 5 and 6 the breakdown of the optimal solution obtained: the penalizing function is zero (all restrictions are met), while the cost function is 1351.02 Euros for the Burgos demand, and 9802.52 Euros for the Valencia and Palma demand. Figure 2 shows the optimal route.

Table 4. Pipe demand from the demand-nodes considered

\begin{tabular}{llll}
\hline $\begin{array}{l}\text { Demand } \\
\text { node }\end{array}$ & Product & Diameter & Amount (lm) \\
\hline Burgos & CIDP & 100 & 3000 \\
Valencia & CIDP-MJ & 150 & 2004 \\
Palma & CIDP-MJ & 150 & 4002 \\
\hline
\end{tabular}

Table 5. Optimal solution for the Burgos demand

\begin{tabular}{llll}
\hline Origin & Destination & Length $(\mathrm{m})$ & Mode of Transport \\
\hline Germany & Bilbao & 3000 & 1 wagon \\
Bilbao & Burgos & 3000 & 3 lorries \\
\hline
\end{tabular}

Table 6. Optimal solution for the Valencia and Palma demand. In Barcelona and Valencia the lorries board the ferry to Palma

\begin{tabular}{llll}
\hline Origin & Destination & Length $(\mathrm{m})$ & Mode of Transport \\
\hline Germany & Barcelona & 6006 & 3 wagons \\
Barcelona & Valencia & 2508 & 3 lorries \\
Barcelona & Palma & 3498 & 4 lorries \\
Valencia & Palma & 504 & 1 lorry \\
\hline
\end{tabular}

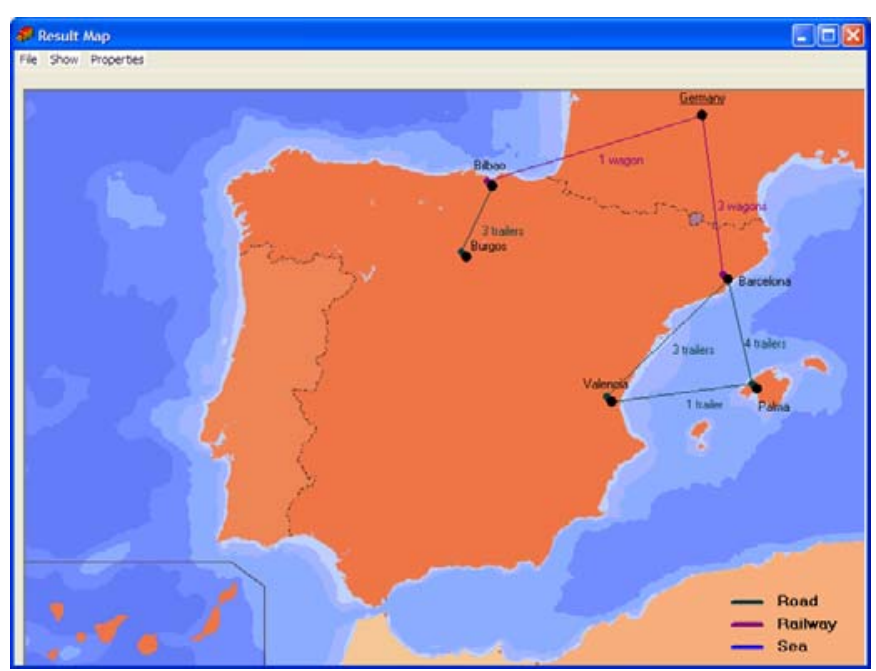

Fig. 2. Visualisation of the optimal route. In Barcelona and Valencia the lorries board a ferry to Palma.

This is a multimodal problem because the solution shown in Tables 7 and 8 is also an optimal solution with the same value of the cost function as the before optimal solution shown in Tables 5 and 6.

Table 7. Optimal solution for the Burgos demand

\begin{tabular}{llll}
\hline Origin & Destination & Length $(\mathrm{m})$ & Mode of Transport \\
\hline Germany & Bilbao & 3000 & 1 wagon \\
Bilbao & Burgos & 3000 & 3 lorries \\
\hline
\end{tabular}


Table 8. Optimal solution for the Valencia and Palma demand. In Barcelona and Valencia the lorries board the ferry to Palma

\begin{tabular}{llll}
\hline Origin & Destination & Length $(\mathrm{m})$ & Mode of Transport \\
\hline Germany & Barcelona & 6006 & 3 wagons \\
Barcelona & Valencia & 2508 & 3 lorries \\
Barcelona & Palma & 3498 & 4 lorries \\
Valencia & Palma & 504 & 1 lorry \\
\hline
\end{tabular}

\section{Conclusions}

We have applied our Flexible Evolution Algorithm (FEA), which has capacity to adapt the operators, the parameters and the algorithm to the circumstances faced at each step of every optimisation run. When the search space is dimensionally very high - as in the problem considered in this paper there is a need for evolutive algorithms with certain learning ingredients, as well as strategies that progressively impose with more and more severity in the evolutive process the real scenario of the complex problem that has to be resolved.

\section{References}

1. B. Galván and G. Winter, Evolución Flexible, Report CEA-04-001 of CEANI-IUSIANI, University of Las Palmas de Gran Canaria, 2001.

2. G. Winter, B. Galván, S. Alonso and B. González, Evolving from Genetic Algorithms to Flexible Evolution Agents, In Late-Breaking Papers of the Genetic and Evolutionary Computation Conference, 466-473 (2002).

3. G. Winter, B. Galván, P.D. Cuesta and S. Alonso, Flexible Evolution, In Evolutionary Methods for Design, Optimization and Control with Applications to Industrial Problems, Barcelona: CIMNE, 89-94 (2002).

4. G. Winter, B. Galván, S. Alonso, B. González, D. Greiner, J.I. Jiménez, Flexible Evolutionary Algorithms: cooperation and competition among real-coded evolutionary operators, In Special Issue on solving real-world optimization problems using Real Coded Genetic Algorithms (RCGAs). Springer-Verlag Heidelberg, Soft Computing, 9(4), 299-323 (2005).

5. D.E. Goldberg and J. Richardson, Genetic algorithms with sharing for multimodal function optimization, In Proceedings of the First International Conference on Genetic Algorithms and Their Applications, 41-49 (1987).

6. G. Winter, J.M. Emperador, B. González, D. Santos, B. Galván, F.O. López, Diseño de un sistema de planificación óptima de transporte de productos mediante Algoritmos Genéticos, Report CEA-12-002 of CEANI-IUSIANI, University of Las Palmas de Gran Canaria, 2002.

7. G. Winter, B. González, B. Galván, J.M. Emperador, Sistema inteligente para la planificación óptima del transporte multimodal de mercancías, In II Technological Innovations Forum for Transport: TRANSNOVA 2005, Las Palmas de Gran Canaria, 2005.

8. B. González, G. Winter, J.M. Emperador, B. Galván, Sistema inteligente para la planificación con coste mínimo del transporte multimodal de tubos, In Proceeding of the IV Congreso Español sobre Metaheurísticas, Algoritmos Evolutivos y Bioinspirados, 945-952 (2005). 